\title{
Experimental investigation of the structural response of adobe buildings to lateral loading before and after the implementation of compatible grout repairs
}

\author{
Rogiros Illampas ${ }^{1}$, Rui A. Silva², Dimos C. Charmpis ${ }^{3}$, Paulo B. Lourenço ${ }^{4}$ and Ioannis Ioannou ${ }^{5}$
}

\begin{abstract}
In the framework of this study, a 1:2 scaled replica of a traditional single-storey adobe building was constructed and tested at the laboratories of the University of Cyprus. The main objectives of the experimental program were to evaluate the structural performance of adobe buildings under horizontal loads (simulating seismic action) and to investigate the effectiveness of cracking repair by means of injection with a compatible grout. The model was initially subjected to a series of monotonic static lateral loading cycles that led to the development of extensive cracking damage and to significant reduction of the load-bearing capacity and overall stiffness. A compatible clay-based grout was then developed using the same soil as the one composing the model's adobes. This material was injected into the cracked sections of the masonry and the repaired model was re-tested. The clay-based grout successfully restored structural continuity, precluding the re-opening of injected cracks during subsequent loading cycles. The recorded load-deformation response revealed that the grout repair reinstated the original stiffness of the structure and recovered more than $90 \%$ of the initial lateral strength. The results indicate that clay-based grouts can be used for re-establishing the stability of adobe constructions under static loads.
\end{abstract}

Keywords: Adobe masonry; grouting repair; clay-based grout; horizontal loading; static tests.

\section{Introduction}

Historic and traditional adobe masonry structures have proven to be rather vulnerable to cracking damage, due to their limited capacity to resist tensile forces and the quasi-brittle nature of their materials. Cracking in such constructions is primarily caused by seismic action, forced displacements (e.g. foundation settlements) and high levels of concentrated static loads [1]. The presence of cracks can significantly affect the performance of adobe masonry as it reduces its load-bearing capacity and stiffness, while providing a path for damage propagation and moisture penetration. Efficient repair of cracking damage is thus considered essential for ensuring the overall stability of adobe buildings.

\footnotetext{
${ }^{1}$ Post-doctoral Researcher, Department of Civil and Environmental Engineering, University of Cyprus, Nicosia, Cyprus, rilamp01@ucy.ac.cy

${ }^{2}$ Post-doctoral Researcher, Department of Civil Engineering, ISISE, University of Minho, Minho, Portugal, ruisilva@civil.uminho.pt

${ }^{3}$ Associate Professor, Department of Civil and Environmental Engineering, University of Cyprus, Nicosia, Cyprus, charmpis@ucy.ac.cy

${ }^{4}$ Professor, Department of Civil Engineering, ISISE, University of Minho, Minho, Portugal, pbl@civil.uminho.pt

${ }^{5}$ Associate Professor, Department of Civil and Environmental Engineering, University of Cyprus, Nicosia, Cyprus, ioannis@ucy.ac.cy
} 
Research has shown that the injection of grouts into cracked earth masonry sections can provide adequate stiffness and strength recovery [2]. Focus has therefore been placed on the development of clay-based grouts that are compatible with masonry materials composed of raw earth. Within this framework, researchers [3-7] have considered the use of both unstabilized grouts constituting of earth and other aggregates, and of claybased grouts stabilized with the addition of cement, lime and gypsum. Experimental data $[2,6]$ indicate that satisfactory results can be achieved with the injection of unstabilized clay-based grouts, in particular, since these materials tend to exhibit good adhesion to adobe bricks and earth mortars.

In this study, the efficiency of injection grouting for the repair of adobe buildings is evaluated via laboratory tests on a 1:2 scaled replica of a traditional dwelling. The structure was subjected to monotonic static horizontal loading cycles resembling seismic thrusts, until a depletion of its overall stiffness and bearing capacity was noted. The cracks induced were then injected with an unstabilized clay-based grout composed of the same soil as the one incorporated in the masonry materials and a new series of loading tests were implemented. The response before and after the injection of the grout is hereby compared in terms of the recorded forcedisplacement experimental data and damage patterns. Useful conclusions regarding the effect of grouting on the global structural behavior of repaired adobe buildings are hence derived.

\section{Model building construction and experimental set-up}

A 1:2 scaled model of a vernacular adobe house (Fig. 1) was built at the Structures Laboratory of the University of Cyprus with the purpose of investigating the response of earthen buildings to lateral loading [8]. The structure has a rectangular layout, measuring $1.75 \mathrm{~m}$ in width and $3.60 \mathrm{~m}$ in length. Its walls are $22 \mathrm{~cm}$ thick and were constructed using scaled-down adobes with dimensions $3 \times 22 \times 15 \mathrm{~cm}^{3}$ (height $\mathrm{x}$ length $\mathrm{x}$ width). These were laid in a running bond pattern with the application of earth mortar. Both the adobes and mortar were composed of a local fine-grained lean clay soil (9\% sand, $63 \%$ silt and $28 \%$ clay) mixed with straw fibers at a ratio of $\sim 5: 1 \mathrm{v} / \mathrm{v}$. The structure's side walls are identical and feature rectangular window openings $0.55 \mathrm{~m}$ wide. The façade wall is $1.50 \mathrm{~m}$ high and incorporates a door opening with dimensions (height $\mathrm{x}$ width) $1.10 \times 0.70 \mathrm{~m}^{2}$. The rear wall has a triangular ventilation notch $0.22 \mathrm{~m}$ wide and $0.18 \mathrm{~m}$ high and is $0.15 \mathrm{~m}$ higher than the façade due to the presence of a single-pitched roof. Above the door and window openings, timber lintels $85 \times 85 \mathrm{~mm}^{2}$ in cross-section were installed. The roof structure consists of timber rafters (45 x $90 \mathrm{~mm}^{2}$ in cross-section) spaced at $0.40 \mathrm{~m}$ intervals that support a $20 \mathrm{~mm}$-thick wooden panel. To account for the weight of roof tiles, the surface of the panel was covered with adobes. All timber members were set into the masonry using gypsum mortar. Prior to testing, a 9 week curing period was allowed to ensure sufficient setting of the masonry.

For the implementation of the loading tests, a hydraulic jack system with $60 \mathrm{kN}$ capacity was used. A timber beam attached on the swivel head of the jack transferred the imposed forces along the length of the rear wall, at the approximate level of the structure's center of mass (i.e. 2/3 of its height) (Fig. 1b). The loading process involved the application of gradually increasing horizontal forces until crack initiation or damage propagation 
was observed. The structure was subsequently fully unloaded and was progressively reloaded up to a force magnitude that resulted to further damage. Load testing at both the initial and repaired states seized when a reduction of the overall lateral resistance was detected. Throughout the experimental procedure, the displacements induced at critical points of the structure were measured using Linear Variable Differential Transducers (LVDTs) (range $\pm 50.8 \mathrm{~mm}$, accuracy $\pm 0.25 \%$ ). Crack development was monitored with digital cameras.

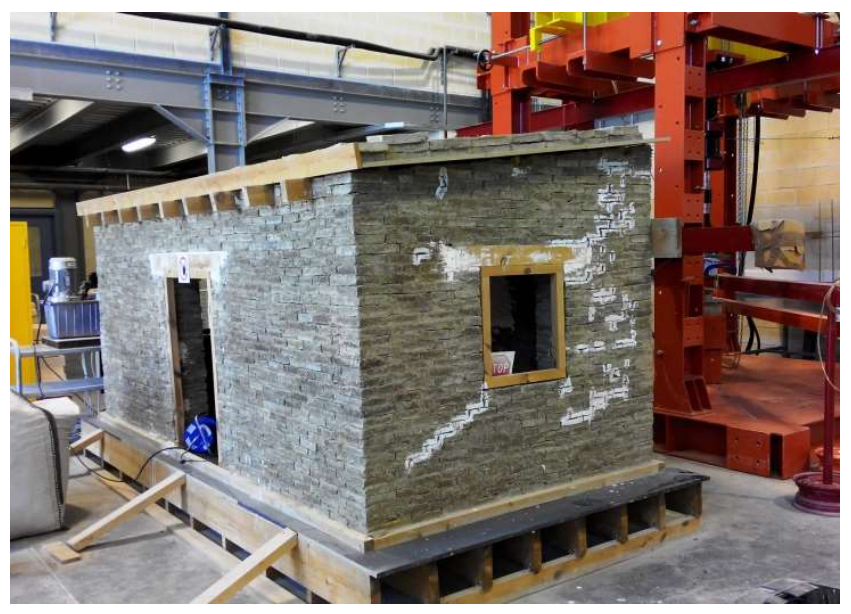

(a)

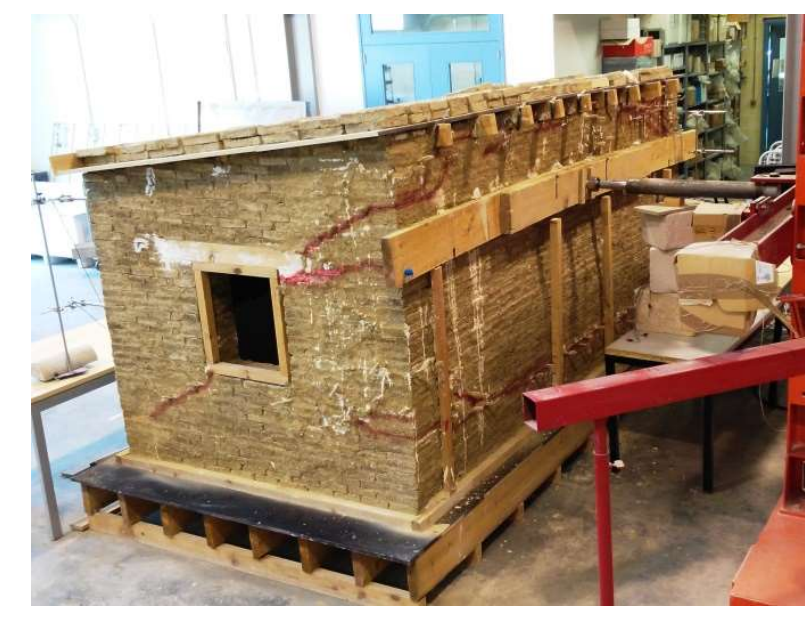

(b)

Figure 1. Front (a) and rear (b) views of the tested scaled adobe building. In the rear view of the structure, the load imposition timber beam and the hydraulic jack used for exerting horizontal forces are shown.

\section{Static tests to induce cracking damage}

The original, undamaged model was subjected to a sequence of ten loading cycles. This resulted to severe cracking of the rear and side walls (Fig. 2). The localization of damage at the aforementioned areas implies a non-uniform load distribution within the members of the structure, verifying that the lack of a roof diaphragm in unreinforced adobe masonry buildings precludes integral box action.

Diagonal shear cracks radiating from the corners of the windows occurred at the side walls loaded in-plane. The rear wall that was loaded out-of-plane sustained horizontal cracking along its base. Horizontal and diagonal cracks were also noted at the interior of the same wall, at the area where the load was imposed. Damage was characterized by loss of cohesion at the brick-mortar interfaces, rather than failure of the masonry materials themselves. Crack opening during the loading phase was significant, reaching $20 \mathrm{~mm}$ at some areas. In addition to masonry cracking, sliding of the roof rafters due to failure of the bonding gypsum mortar was observed.

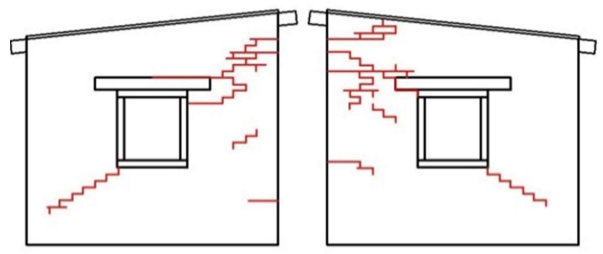

Side walls

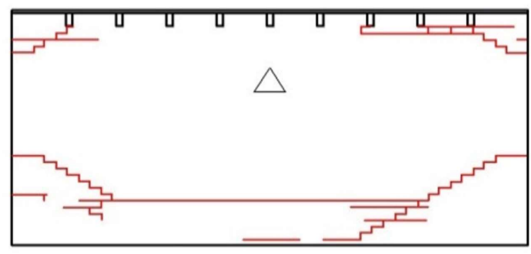

Rear wall exterior

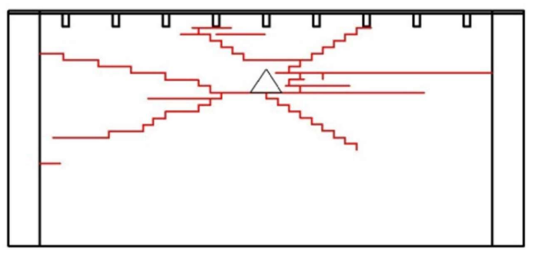

Rear wall interior

Figure 2. Crack pattern recorded after the completion of the initial static lateral loading test cycles. 
(a)
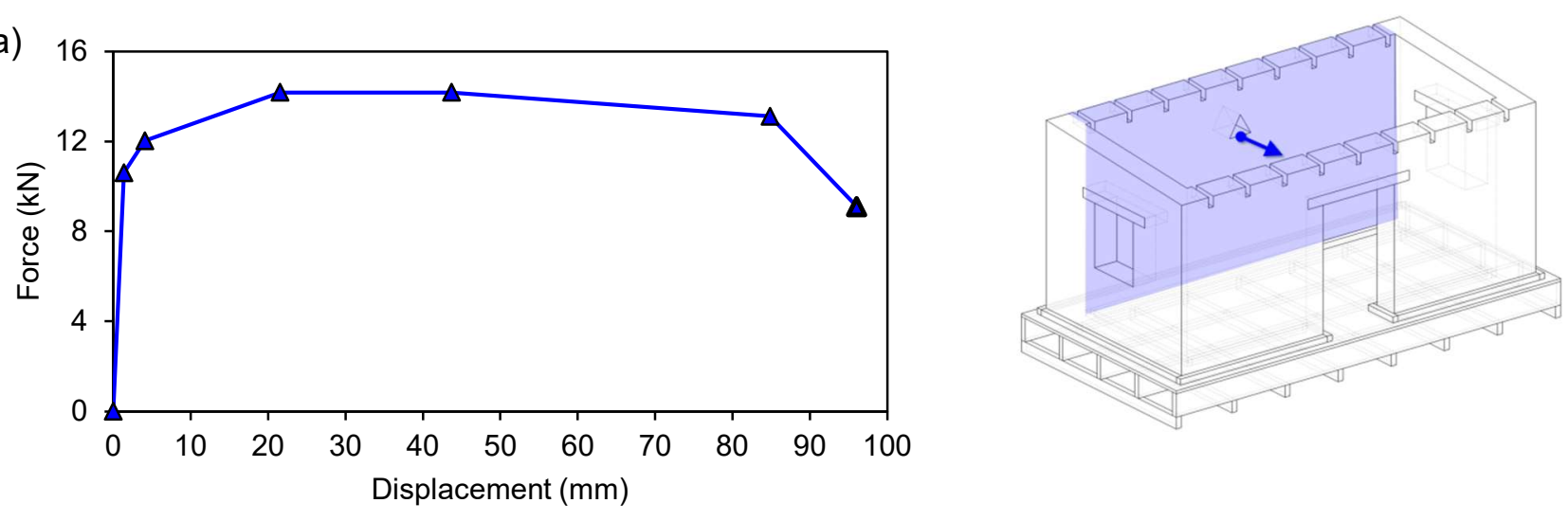

(b)
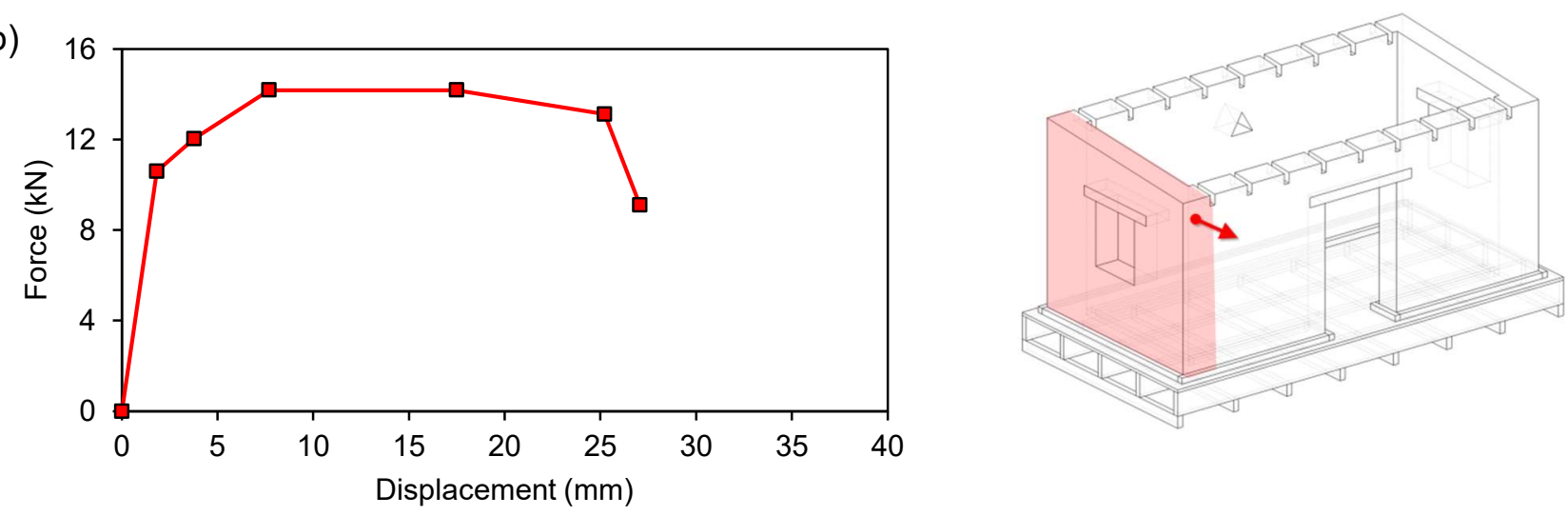

(c)
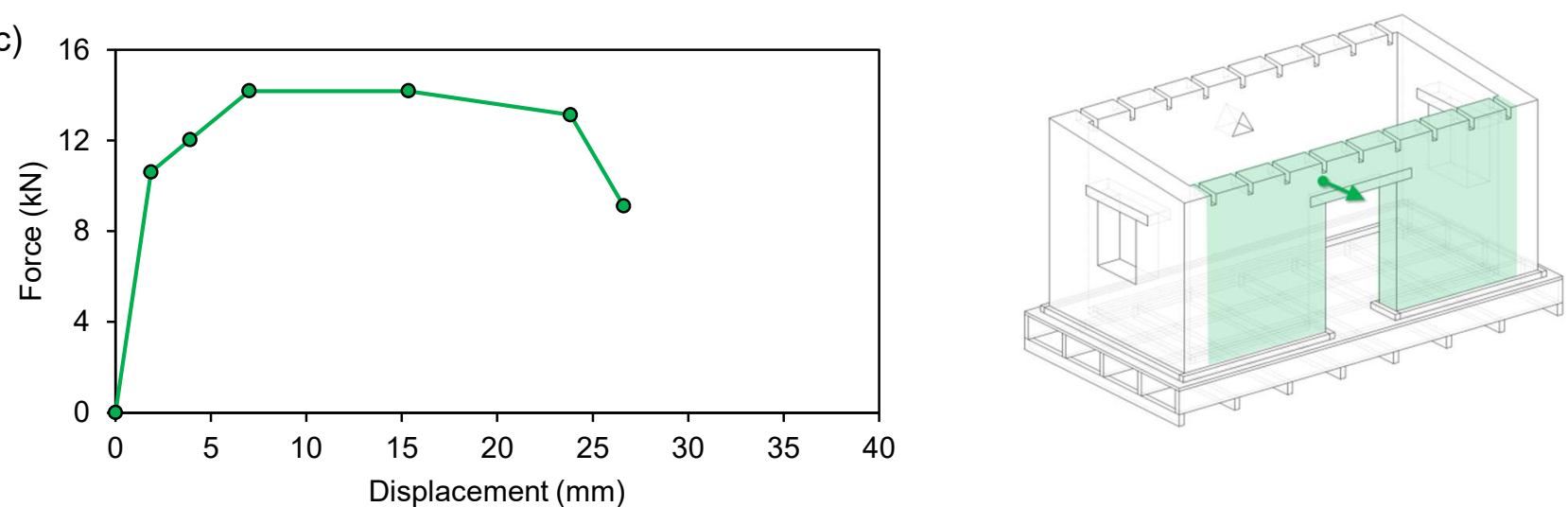

Figure 3. Force-displacement data envelopes for the rear (a), side (b) and façade (c) walls obtained from the initial load testing of the original model building. The positions where displacement measurements were carried out are shown in the corresponding pictures and the characteristic data points $(\boldsymbol{\Lambda}, \mathbf{\square}, \bullet)$ which have been used to form the force-displacement envelopes are noted in the diagrams.

The initial maximum lateral resistance of the tested structure was $14.2 \mathrm{kN}$ and accounts for approximately $30 \%$ of its self-weight. The recorded force-displacement data (Fig. 3) imply a nominal yielding point at a load magnitude of $10.6 \mathrm{kN}$ and a displacement level of $1.8 \mathrm{~mm}$. From this point onwards, stiffness degradation and cracking damage started to develop. Up to approximately $12 \mathrm{kN}$, a rather uniform deformation distribution was noted, as the walls exhibited coinstantaneous translation sustaining lateral displacements $<4 \mathrm{~mm}$. When the imposed force increased above the aforementioned value, homogenous response of the structural system was lost and differential movement of the walls and roof members took place. After the load-bearing capacity was exceeded, a rocking mechanism was formed due to splitting of the two side walls, as a result of extensive 
crack propagation. Subsequently, the overall lateral resistance fell to a residual value of $9.1 \mathrm{kN}$. At this stage, the ultimate out-of-plane translation measured at the rear wall's upper central section was $96 \mathrm{~mm}$, while the displacements generated at the upper part of the side and façade walls were in the region of $26 \mathrm{~mm}$.

\section{Testing of repaired building}

\subsection{Repair procedure}

The design of the grout used for the repair of the building was based on previous work by Silva et al. [2, 3]. To ensure full compatibility with the materials composing the structure under study, the grout mixture incorporated the same soil as the one used in the fabrication of the adobe bricks and bedding mortar. The solid constituents of the grout consisted of 30\% lean clay soil sieved through $0.18 \mathrm{~mm}$ mesh and $70 \%$ fine limestone powder $(d<0.025 \mathrm{~mm})$. Approximately $5 \mathrm{~g}$ of sodium hexametaphosphate were added into the mixture for every $1 \mathrm{~kg}$ of solid constituents in order to reduce the water-to-solids (w/s) ratio and improve fluidity. A w/s ratio of about 0.45 was used. The properties of the fresh and hardened grout are reported in Table 1.

Table 1. Average properties of the clay-based grout (Coefficient of Variation).

\begin{tabular}{|c|c|c|}
\hline Property (unit) & Assessment method & Average value (COV) \\
\hline Flow time (s) & ASTM D854 [9] & $104(13 \%)$ \\
\hline Apparent density $\left(\mathrm{kg} / \mathrm{m}^{3}\right)$ & Gravimetric measurement & $1575(3 \%)$ \\
\hline Compressive strength $(\mathrm{MPa})$ & EN 1015-11 [10] & $2.21(7 \%)$ \\
\hline Bending strength $(\mathrm{MPa})$ & EN 1015-11 [10] & $1.28(6 \%)$ \\
\hline
\end{tabular}

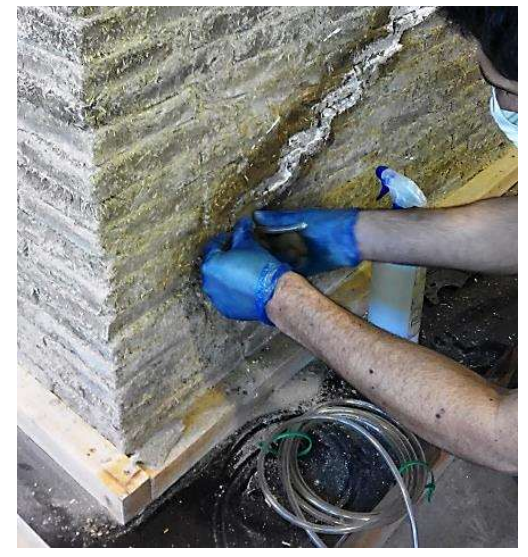

(a)

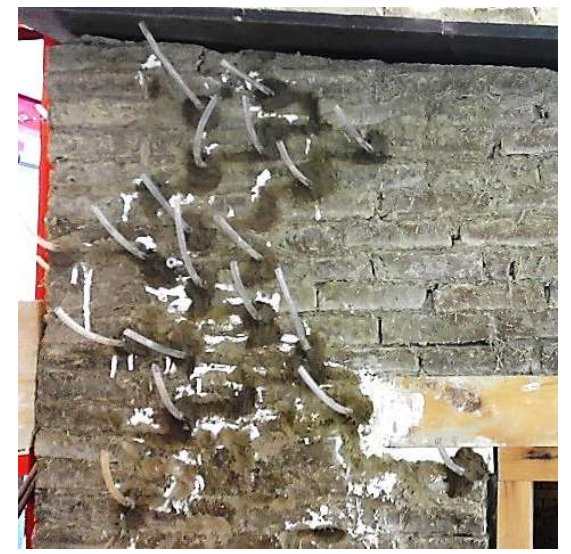

(b)

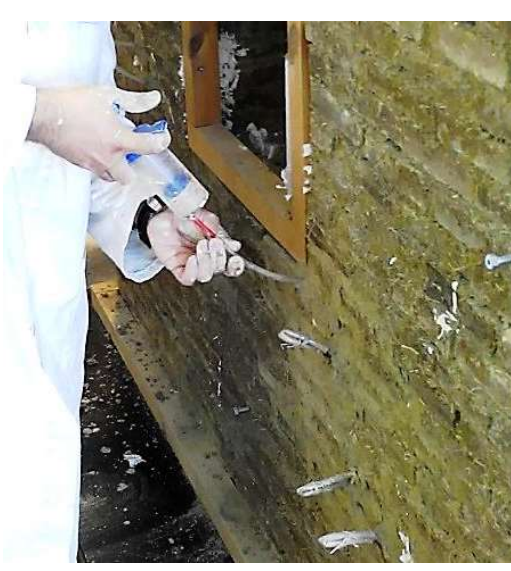

(c)

Figure 4. Crack repair procedure: installation of plastic tubes along crack paths (a), sealing of cracks with earth mortar (b) and injection of clay-based grout (c).

The grout was injected at all recorded crack paths and at the abutments of the roof rafters. Initially, cracks were cleaned from loose debris using pressurized air. Flexible plastic tubes with $5 \mathrm{~mm}$ diameter that extended up to the mid-thickness of the masonry were then inserted every $50-100 \mathrm{~mm}$ along the length of the cracks (Fig. 4a). Earth mortar was used for setting the plastic tubes in place and for sealing the external surfaces of the cracks (Fig. 4b). The grout was injected into the fissures via the plastic tubes using a $100 \mathrm{~mL}$ syringe (Fig. 4c). In each case, the injection procedure started at the bottom-end of a crack, moving upwards, until all tubes 
along the failure path had been filled with grout. Prior to the application of the grout, water was injected to mitigate water adsorption from the grout by the masonry.

\subsection{Lateral loading of grout injected building}

Tests on the repaired structure were conducted 42 days after completion of the grout injection. The repaired building was subjected to an additional four loading cycles.

Comparing the crack pattern recorded before and after the repair intervention, it is noted that grouting did not significantly alter the distribution of damage within the masonry walls (Fig. 5). Again, diagonal cracking was observed at the side walls and a major horizontal crack occurred along the base of the rear wall. In addition, horizontal and diagonal cracks were formed at the interior of the rear wall due to overstressing at the loading area. However, in the repaired structure horizontal cracking also occurred at the upper exterior part of the rear wall, below the abutments of the roof rafters. This is possibly because the clay-based grout injected in this region produced better bonding between the adobes and the timber elements, enabling a more efficient transfer of stresses to the masonry and preventing sliding at relatively low levels of loading. Lateral loading led to significant crack openings, ranging from 4 to $25 \mathrm{~mm}$. Despite the concentration of damage at approximately the same wall sections, cracking did not propagate through the injected failure paths. Instead, new cracks developed through adjacent mortar joints. In all cases, bonding failure at the interfaces between the adobe bricks and the mortar or the grout was observed. Failure of the grout material itself or mitigation of damage to the masonry constituents was not recorded.

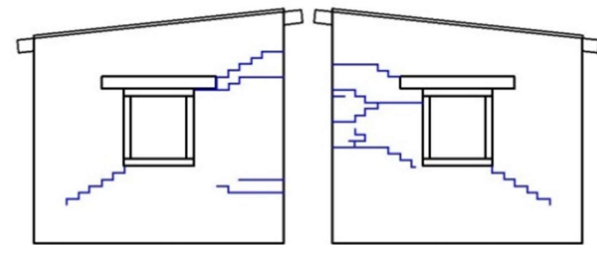

Side walls

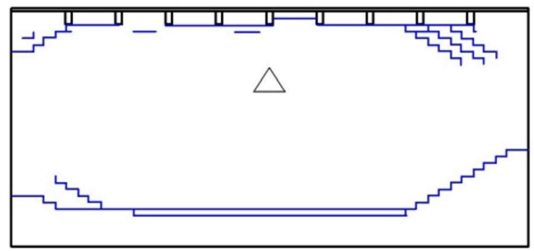

Rear wall exterior

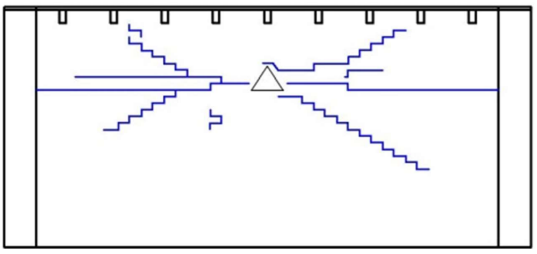

Rear wall interior

Figure 5. Crack pattern recorded after the completion of static lateral loading tests on the repaired structure.

The force-displacement response obtained from the tests conducted after the grout repairs is compared against corresponding data for the original building in Fig. 6. Grouting succeeded in recovering a significant portion of the structure's original strength. The maximum lateral force sustained by the repaired building was $13.2 \mathrm{kN}$ and accounts for $93 \%$ of the initial load-bearing capacity. This is also $45 \%$ higher than the residual strength recorded at the end of the first ten loading cycles. The members of the repaired structure exhibited a homogenous response to loading up to a lateral translation of $9 \mathrm{~mm}$, corresponding to a $12 \mathrm{kN}$ imposed force. Grouting reinstated the initial stiffness of the rear and side walls and increased the out-of-plane stiffness of the façade. The response noted in the latter case is possibly associated with the improved connection between the masonry and the roof that was achieved via the injection of grout at the rafters' abutments. This enabled a more effective distribution of loads to all parts of the building, leading to consistent structural response up to the point where the tensile capacity of the masonry sections supporting the roof was exceeded and horizontal cracking developed. After this stage, rapid damage propagation was observed and significantly large differen- 
tial displacements of the walls were generated. At the final test cycle, a residual capacity of $11.6 \mathrm{kN}$ was recorded. The ultimate displacements measured at the upper sections of the rear, façade and sidewalls were 83 , 32 and $28 \mathrm{~mm}$, respectively.
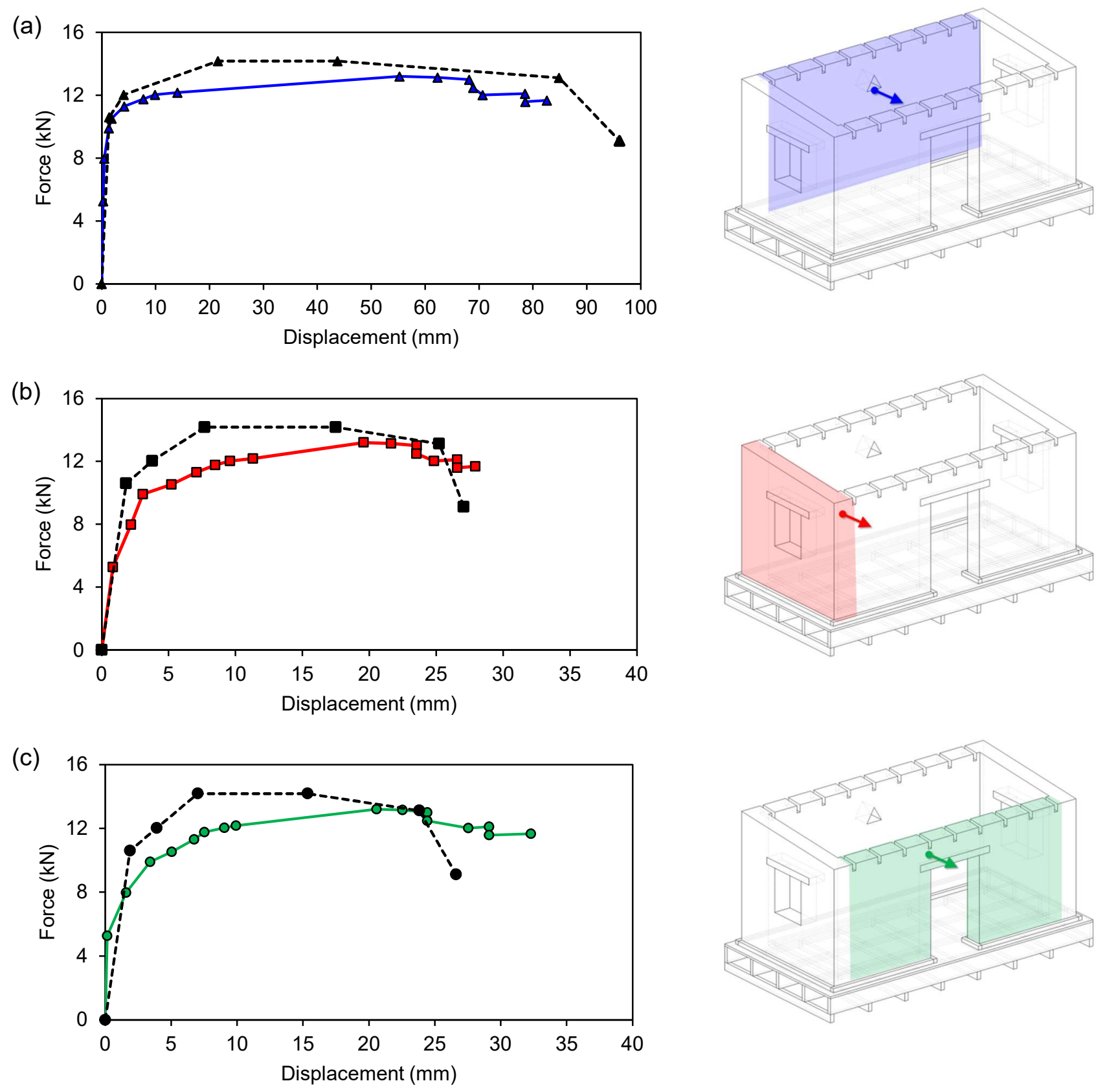

Figure 6. Comparison between the force-displacement data envelopes recorded at the rear (a), side (b) and façade (c) walls following the testing of the original (dotted lines) and the repaired (continuous lines) building. The positions where displacement measurements were carried out are shown in the corresponding pictures and the characteristic data points $(\boldsymbol{\Lambda}, \boldsymbol{\bullet}, \bullet)$ which have been used to form the force-displacement envelopes, are noted in the diagrams.

The high strength recovery rate hereby achieved is primarily attributed to the efficient repair of the in-plane resisting elements (i.e. side walls). Indeed, data reported in the literature verify that clay-based grouts can reinstate the shear resistance of cracked earth masonry $[2,6]$. Shake table tests carried out on an adobe house also repaired with the injection of unstabilized clay-based grout resulted to $54 \%$ strength recovery and $30 \%$ stiffness recovery [7]. These values are considerably lower compared to the outcomes obtained in this study. 


\section{Conclusions}

Monotonic static lateral loading tests were conducted on a 1:2 scaled adobe building before and after the implementation of injection repairs with a compatible unstabilized clay-based grout. The response of the structure under horizontal loads was characterized by cracking due to weak bonding among the masonry units and lack of diaphragmatic function that led to differential movement of the walls. The grout used in this study restored more than $90 \%$ of the original structure's overall load resistance and fully re-established the initial stiffness of the walls. Furthermore, grouting succeeded in strengthening the connection between the roof's timber beams and adobe masonry. Results indicate that the proposed repair methods can improve the structural performance of damaged adobe buildings by reinstating the monolithic behavior of cracked sections and/or by enhancing the bond between the load-bearing elements.

\section{Acknowledgments}

This study was partly financed by FEDER funds through the Competitivity Factors Operational Programme COMPETE, and by national funds through FCT - Foundation for Science and Technology, within the scope of the projects POCI-01-0145-FEDER-007633 and POCI-01-0145-FEDER-016737 (PTDC/ECMEST/2777/2014). The support from grant SFRH/BPD/97082/2013 is also acknowledged.

\section{References}

[1] Illampas, R., Ioannou, I., Charmpis, DC. (2013) Overview of the pathology, repair and strengthening of adobe structures. International Journal of Architectural Heritage 7(2), 165-188.

[2] Silva, RA., Oliveira, DV., Schueremans, L., Miranda, T., Machado, J. (2016) Effectiveness of the repair of unstabilised rammed earth with injection of mud grouts. Construction and Building Materials 127, 861-871.

[3] Silva, RA., Schueremans, L., Oliveira, DV., Dekoning, K., Gyssels, T. (2012) On the development of unmodified mud grouts for repairing earth constructions: rheology, strength and adhesion. Materials and Structures 45(10), 1497-1512.

[4] Roselund, N. (1990) Repair of cracked adobe walls by injection of modified mud. In: Proceedings of the 6th International Conference on the Conservation of Earthen Architecture, New Mexico, U.S.A., 14-19 October.

[5] Jäger, W., Fuchs, C. (2008) Reconstruction of the Sistani House at Bam Citadel after the collapse due to the earthquake 2003. In D'Ayala, D., Fodde, E., eds.: Structural Analysis of Historic Construction. Taylor \& Francis Group, London 1181-1187.

[6] Vargas, J., Blondet, M., Cancino, C., Ginocchio, F., Iwaki, C., Morales, K. (2008) Experimental results on the use of mud-based grouts to repair seismic cracks on adobe walls. In D'Ayala, D., Fodde, E., eds.: Structural Analysis of Historic Construction. Taylor \& Francis Group, London 1095-1099.

[7] Blondet, M., Vargas, J., Groenenberg, RJ. (2012) Evaluation of the efficacy of mud injection to repair seismic cracks on adobe structures via full-scale shaking table tests. In: Proceedings of the 15th World Conference on Earthquake Engineering, Lisbon, Portugal, 24-28 September.

[8] Illampas, R., Charmpis, DC., Ioannou, I. (2014b) Laboratory testing and finite element simulation of the structural response of an adobe masonry building under horizontal loading. Engineering Structures 80(1), 362-376.

[9] ASTM D854 (2002) Standard Test Methods for Specific Gravity of Soil Solids by Water. ASTM International, http://www.astm.com, West Conshohocken, PA.

[10]EN 1015-11 (1999) Methods of test for mortar for masonry - Part 11: Determination of flexural and compressive strength of hardened mortar. CEN, Brussels. 